\title{
Highlight report: biomarkers of acetaminophen-induced liver injury
}

\author{
H. M. Bolt ${ }^{1}$
}

Published online: 3 November 2015

(C) Springer-Verlag Berlin Heidelberg 2015

A comprehensive review about translational biomarkers of acetaminophen-induced acute liver damage has been published in our journal (Beger et al. 2015). Currently, diagnosis of APAP overdose is still based on the analysis of acetaminophen (APAP) levels in blood (Rumack et al. 1981) and on the elevation of the liver enzyme alanine aminotransferase (Zyoud et al. 2012). Analysis of APAP and alanine aminotransferase (ALT) in blood serves as a basis of decision making by clinicians, for example, whether the antidote $N$-acetylcysteine should be administered (Beger et al. 2015). However, a limitation of the use of APAP and ALT in clinical routine is that interpretation of these makers depends on the knowledge of the exact time of intoxication, because both APAP and ALT in blood are strongly time dependent (Beger et al. 2015). Therefore, the identification of novel biomarkers of APAP intoxication, which can be interpreted independently from the time point of overdose, or even in a setting of long-term exposure to APAP, still represents a cutting-edge topic. In their review Beger et al. (2015) discuss the discovery and validation process of new biomarkers with the following key messages:

- Acylcarnitines represent a promising development, because they occur earlier in human blood after APAP intoxication than the conventional diagnostic marker ALT and is back to near normal when ALT reaches it maximum. Therefore, acylcarnitines inform about the early phase of an acute intoxication. Acylcarnitines

\footnotetext{
H. M. Bolt

bolt@ifado.de

1 Leibniz Research Centre for Working Environment and Human Factors at TU Dortmund, IfADo, Ardeystr. 67, 44139 Dortmund, Germany
}

represent fatty acid metabolites that are transported into the mitochondria for beta-oxidation (Beger et al. 2015). Since oxidative stress of mitochondria represents an early step in APAP-induced hepatotoxicity (Godoy et al. 2013), the increase in blood acylcarnitines represents a mechanistically well-understood biomarker.

- MiR-122 is one of the dominating miRNAs of the liver (Beger et al. 2015). It represents approximately $75 \%$ of total liver miRNAs. Several studies have shown a transient increase after APAP intoxication in animal models; however, clinical research is required to learn whether miRNAs give additional information over the conventional biomarker ALT.

- Bile acids as biomarkers of APAP-induced liver damage represent a further promising field of research. Particularly, total bile acids, glycochenodeoxycholic acid and taurochenodeoxycholic acid represent intensively studied candidate biomarkers.

Research on the molecular mechanisms of acetaminophen toxicity still represents a cutting-edge topic in our journal (Lancaster et al. 2015; Hwang et al. 2014; Sjogren et al. 2014; McGill et al. 2014; Schyschka et al. 2013; Singh et al. 2013). Moreover, large efforts are undertaken to establish in vitro systems for hepatotoxicity testing (Ramaiahgari et al. 2014; Grinberg et al. 2014; Tolosa et al. 2013; Hewitt et al. 2007; Godoy et al. 2015; Schug et al. 2013) and elucidating mechanisms of hepatotoxicity (Rodrigues et al. 2013; Ghallab 2014a, b; Reif 2014a, b; Godoy 2011). Besides its clinical relevance, the translational biomarkers discussed in the review of Beger et al. (2015) are also of high interest for scientists optimizing in vitro systems for hepatotoxicity testing. 


\section{References}

Beger RD, Bhattacharyya S, Yang X, Gill PS, Schnackenberg LK, Sun J, James LP (2015) Translational biomarkers of acetaminophen-induced acute liver injury. Arch Toxicol 89(9):14971522. doi:10.1007/s00204-015-1519-4

Ghallab A (2014a) The rediscovery of HepG2 cells for prediction of drug induced liver injury (DILI). EXCLI J 13:1286-1288

Ghallab A (2014b) Human non-parenchymal liver cells for co-cultivation systems. EXCLI J 13:1295-1296

Godoy P (2011) Hepatotoxicity. EXCLI J 10:124-127

Godoy P, Hewitt NJ, Albrecht U et al (2013) Recent advances in 2D and $3 \mathrm{D}$ in vitro systems using primary hepatocytes, alternative hepatocyte sources and non-parenchymal liver cells and their use in investigating mechanisms of hepatotoxicity, cell signaling and ADME. Arch Toxicol 87(8):1315-1530. doi:10.1007/ s00204-013-1078-5

Godoy P, Schmidt-Heck W, Natarajan K, Lucendo-Villarin B, Szkolnicka D, Asplund A, Björquist P, Widera A, Stöber R, Campos G, Hammad S, Sachinidis A, Chaudhari U, Damm G, Weiss TS, Nüssler A, Synnergren J, Edlund K, Küppers-Munther B, Hay DC, Hengstler JG (2015) Gene networks and transcription factor motifs defining the differentiation of stem cells into hepatocyte-like cells. J Hepatol 63(4):934-942. doi:10.1016/j. jhep.2015.05.013

Grinberg M, Stöber RM, Edlund K et al (2014) Toxicogenomics directory of chemically exposed human hepatocytes. Arch Toxicol 88(12):2261-2287. doi:10.1007/s00204-014-1400-x

Hewitt NJ, Lechón MJ, Houston JB, Hallifax D, Brown HS, Maurel P, Kenna JG, Gustavsson L, Lohmann C, Skonberg C, Guillouzo A, Tuschl G, Li AP, LeCluyse E, Groothuis GM, Hengstler JG (2007) Primary hepatocytes: current understanding of the regulation of metabolic enzymes and transporter proteins, and pharmaceutical practice for the use of hepatocytes in metabolism, enzyme induction, transporter, clearance, and hepatotoxicity studies. Drug Metab Rev 39(1):159-234 (Review)

Hwang JH, Kim YH, Noh JR, Gang GT, Kim KS, Chung HK, Tadi S, Yim YH, Shong M, Lee CH (2014) The protective role of $\mathrm{NAD}(\mathrm{P}) \mathrm{H}$ :quinone oxidoreductase 1 on acetaminophen-induced liver injury is associated with prevention of adenosine triphosphate depletion and improvement of mitochondrial dysfunction. Arch Toxicol, 17 Sept 2014 [Epub ahead of print]

Lancaster EM, Hiatt JR, Zarrinpar A (2015) Acetaminophen hepatotoxicity: an updated review. Arch Toxicol 89(2):193-199. doi:10.1007/s00204-014-1432-2

McGill MR, Li F, Sharpe MR, Williams CD, Curry SC, Ma X, Jaeschke H (2014) Circulating acylcarnitines as biomarkers of mitochondrial dysfunction after acetaminophen overdose in mice and humans. Arch Toxicol 88(2):391-401. doi:10.1007/ s00204-013-1118-1
Ramaiahgari SC, den Braver MW, Herpers B, Terpstra V, Commandeur JN, van de Water B, Price LS (2014) A 3D in vitro model of differentiated HepG2 cell spheroids with improved liver-like properties for repeated dose high-throughput toxicity studies. Arch Toxicol 88(5):1083-1095. doi:10.1007/s00204-014-1215-9

Reif R (2014a) Concepts of predictive toxicology. EXCLI J 13:1292-1294

Reif R (2014b) The body-on-a-chip concept: possibilities and limitations. EXCLI J 13:1283-1285

Rodrigues AV, Rollison HE, Martin S, Sarda S, Schulz-Utermoehl T, Stahl S, Gustafsson F, Eakins J, Kenna JG, Wilson ID (2013) In vitro exploration of potential mechanisms of toxicity of the human hepatotoxic drug fenclozic acid. Arch Toxicol 87(8):1569-1579. doi:10.1007/s00204-013-1056-y

Rumack BH, Peterson RC, Koch GG, Amara IA (1981) Acetaminophen overdose. 662 cases with evaluation of oral acetylcysteine treatment. Arch Intern Med 141(3 Spec No):380-385

Schug M, Stöber R, Heise T, Mielke H, Gundert-Remy U, Godoy P, Reif R, Blaszkewicz M, Ellinger-Ziegelbauer H, Ahr HJ, Selinski S, Günther G, Marchan R, Blaszkewicz M, Sachinidis A, Nüssler A, Oberemm A, Hengstler JG (2013) Pharmacokinetics explain in vivo/in vitro discrepancies of carcinogen-induced gene expression alterations in rat liver and cultivated hepatocytes. Arch Toxicol 87(2):337-345. doi:10.1007/s00204-012-0999-8

Schyschka L, Sánchez JJ, Wang Z, Burkhardt B, Müller-Vieira U, Zeilinger K, Bachmann A, Nadalin S, Damm G, Nussler AK (2013) Hepatic 3D cultures but not 2D cultures preserve specific transporter activity for acetaminophen-induced hepatotoxicity. Arch Toxicol 87(8):1581-1593. doi:10.1007/s00204-013-1080-y

Singh Y, Braeuning A, Schmid A, Pichler BJ, Schwarz M (2013) Selective poisoning of Ctnnb1-mutated hepatoma cells in mouse liver tumors by a single application of acetaminophen. Arch Toxicol 87(8):1595-1607. doi:10.1007/s00204-013-1030-8

Sjogren AK, Liljevald M, Glinghammar B, Sagemark J, Li XQ, Jonebring A, Cotgreave I, Brolén G, Andersson TB (2014) Critical differences in toxicity mechanisms in induced pluripotent stem cell-derived hepatocytes, hepatic cell lines and primary hepatocytes. Arch Toxicol 88(7):1427-1437. doi:10.1007/ s00204-014-1265-z

Tolosa L, Gómez-Lechón MJ, Pérez-Cataldo G, Castell JV, Donato MT (2013) HepG2 cells simultaneously expressing five P450 enzymes for the screening of hepatotoxicity: identification of bioactivable drugs and the potential mechanism of toxicity involved. Arch Toxicol 87(6):1115-1127. doi:10.1007/ s00204-013-1012-x

Zyoud SH, Awang R, Sulaiman SA (2012) Reliability of the reported ingested dose of acetaminophen for predicting the risk of toxicity in acetaminophen overdose patients. Pharmacoepidemiol Drug Saf 21(2):207-213. doi:10.1002/pds.2218 